\title{
Über Brüche
}

des

\section{knöchernen Trommelfellrandes}

\author{
Ein Beitrag zur Unfall-Lehre
}

\author{
Von \\ Prof. Dr. Heinrich Walb \\ Geheimer Medizinalrat, \\ Direktor der Universitäts-Poliklinik für Ohren-, Hals- und \\ Nasenkranke in Bonn
}

Mit 18 Figuren auf 4 Tafeln

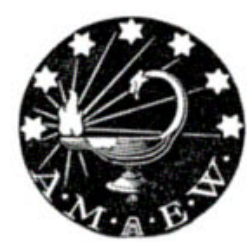

Bonn 1914

A. Marcus \& E. Webers Verlag

Dr. jur. Albert Ahn 


\section{Druck: Oto Wlgand m.b.H., Lelpzig.}

